\title{
STANDARDIZATION RESEARCH - PROCESS AND SERVICE STANDARDIZATION ON THE ADVANCE
}

\author{
GEPP, M[ichael]; STEINMANN, F[lorian]; VOLLMAR, J[an] \& VOIGT, K[ai] - I[ngo]
}

\begin{abstract}
Standardization is a common approach in industry to manage complexity. It enables enterprises to realize e.g. costsavings and quality improvements. Numerous empirical studies examining different aspects of standardization have been carried out, but the research landscape itself has not been subject of many studies yet. This article gives an overview of standardization research activities over the last decades. The analysis of the distribution of research activities in the different fields of standardization research - product, process and service - will be of special interest. The study is based on a quantitative approach. The number of publications in the mentioned research fields is determined in three different online portals for academic literature. This study adds empirical evidence to existing assumptions of various authors about the current research landscape and possible topics of future research. Findings reveal that the number of publications referring to standardization in general is increasing strongly. Further research on process standardization seems to be on the advance, since the number of annual publications on process standardization exceeds those related to product standardization for a couple of years. Publications on service standardization are underrepresented compared to the other fields. But there are indicators that it will become more important in the near future.
\end{abstract}

Keywords: research activities, standardization, process, product, service

\section{INTRODUCTION}

Standardization is a common approach in industry to achieve cost-savings, quality improvements and a shorter time-to-market. These benefits result from an improved management of complexity [1][2].

Since standardization became subject of research during the industrial revolution, various fields of research emerged [3]. Especially since the contributions by David, Farrell and Saloner in the mid-eighties literature on standardization has increased [4][5][6]. Nowadays the term standardization is widely used in business economics and engineering. But the large and complex body of literature on standardization is leading to different meanings or synonymic use in literature and current language. Therefore a definition of the term standardization is necessary [7]. Since this study has an industrial focus the definition of standardization is based on ISO EN 45020.

According to ISO EN 45020 standardization is the óactivity of establishing, with regard to actual or potential problems, provisions for common and repeated use, aimed at the achievement of the optimum degree of order in a given contextô [8].

It improves óthe suitability of products, processes and services for their intended purposes, prevention of barriers to trade and facilitation of technological cooperationô [8].

The object of standardization can be a product, a process or a service [8][9].

\section{RESEARCH AREAS}

Based on the object of standardization, the following three categories of research activities (hereafter called óresearch fieldsô) in standardization research can be differentiated [8][9]:

- product standardization

- process standardization

- $\quad$ service standardization

The following paragraphs characterize these research fields, before the research activities in these fields are evaluated.

\section{FIELDS OF STANDARDIZATION RESEARCH}

3.1 What is product standardization?

Product standardization is the process of setting uniform characteristics for a particular good. Such uniform products can be produced in large quantities by exploiting economies of scale, making product standardization an efficient method to reduce costs and increase quality [2][5].

Product standardization research focuses on approaches to limit product variety to a certain range or number of characteristics (e.g. size, quality level) of product parts or complete products [10]. Common strategies to implement product standardization on this technical level are common parts and platforms concepts or modularization.

A central role in product standardization research plays the concept of mass customization $\tilde{n}$ producing customized goods for a mass market. It allows companies to balance the need for targeted adaptation to customer needs with the cost savings of standardization [11][12].

\subsection{What is process standardization?}

Process standardization concentrates on the realization of a uniform and transparent process landscape. It is part of the domains (business) process management and business process modeling. In contrast to product standardization the object of standardization is a process. This can be an internal process of a company (e.g. engineering) or processes between enterprises (e.g. cooperation with suppliers) [13]. 
The development of an optimized process landscape is the main subject of research in this field. By the identification and the definition of process activities which are suitable for reuse, companies can achieve reproducible high performances and quality [13].

Standardized process activities and interfaces lead to a less complex exchange of goods and services between business units as well as external customers, suppliers and partners. The increased process efficiency is reflected in a reduction of transaction costs and a transparent process flow [14].

\subsection{What is service standardization?}

A service is an intangible commodity. Its characteristics are perishability, inseparability, simultaneity and variability [16][17]. Due to these special characteristics standardization of services is difficult.

To make services comparable, to simplify the electronic and worldwide trade of services and to define the range and the content of services standardization is necessary [16]. A pioneer in service standardization is the financial world, where financial services are well standardized. This leads to a large amount of international trade of financial services.

\section{NEED FOR RESEARCH}

It seems safe to say that the complexity of products, processes and services in an industrial environment is increasing. The cause of the increasing complexity lies i.a. in megatrends like globalization, individualization of customer needs, or the technological change. Globalization for instance promotes globally distributed engineering activities and leads to organizational complexity. Others like individualization of customer needs and technological change lead to complexity on a technical level (e.g. product variety, number of components in a system, share of mechatronic components) [15]. Since standardization is an approach to manage this complexity, researchers assume that it has become increasingly important, too [10][18][19].

Recently, researchers and practitioners alike have shown more and more interest in the fields of process and service standardization.

Muenstermann for instance states that process standardization increasingly draws attention on itself [13]. Process standardization research is especially interested in issues like potential value, design or impact of process standardization [14][20][21].

Service standardization is seen as a second emerging research field mainly for two reasons. First, the undisputed shift of the industrial economy to a service economy in various developed countries leads to a rising number of services and more complexity in service management [1] [22].

Second, globalization leads to the fact that more and more companies outsource respectively source production activities and services. Since standardized services enable efficient sourcing, service standardization is seen on the advance [22].

The mentioned points indicate that research on standardization in general and on processes and services in particular is increasing. However, these statements were not verified by empirical studies yet. In this contribution we try to answer the following questions:

1. Is the intensity of standardization research in general increasing?

2. How are research activities distributed in the three fields of standardization research?

3. Which fields of research will be of special interest for future research?

\section{RESEARCH METHODOLOGY}

Unlike other meta-studies on standardization research, we did not choose a literature review in this article. This study rather follows a descriptive approach, conducting a quantitative analysis of research activities in the different research fields over the last decades.

It is assumed that the importance of a topic correlates with the intensity of research activities. The intensity of research is represented by the number of publications in the corresponding research field. It is supposed that the intensity of academic research is proportional to the number of publications with a reference to one or more of the three topics: product standardization, process standardization and service standardization.

The number of publications was determined in three databases for academic literature. The following databases were chosen:

1. GoogleScholar (http://scholar.google.de)

2. Ebscohost (http://search.ebscohost.com)

3. ProQuest (http://www.proquest.co.uk/en-UK)

GoogleScholar was chosen as the main database because it provides a high available quantity of publications. At the beginning of GoogleScholar, its suitability for academic use was discussed controversially. Nowadays it is considered to be a good source for systematic literature study especially since it covers a wider variety and range of publications than other academic portals [23][24]. The two other databases were used to validate the collected data.

Corresponding to the definition of standardization of DIN, only literature related to the subjects business economics and industry was considered. Other subjects like biology or medicine were excluded from our search.

Hence, the search in Google Scholar was limited on the subjects óBusiness, Administration, Finance, and Economicsô and óEngineering, Computer Science, and Mathematicsô. For Ebscohost the databases óBusiness Source Completeô and óEconLitô were used. The search in Proquest was based on the economics literature.

The data were collected during March / April 2012. For all databases the search term consisted of the key words ["Product standardi?ation" OR "standardi?ation of products"] $\tilde{n}$ this is the search term for research field product standardization, the search terms of the other fields were analogue to this.

For every year from 1975 to 2011 and for every field of research the number of search results was determined. To avoid that citations were counted, the search was only conducted in the summaries and continuous text of the publications. 
In this inspection we omitted a detailed analysis of the content for each result for brevity reasons. As the target of this study is not a meta-analysis of the contents of the publications, the focus lies on a statistical analysis of publications with a relation to the standardization research topics.

However, to assess the quality of the search results, we randomly selected five years and analyzed in detail whether the results were suitable for this study. After this manual check, we assessed that the total discard is around $10 \%$. I.e. the subject of around $10 \%$ of all search results did not correspond to the understanding of standardization used in this study. Because the discard was nearly equal for all five years and search terms, it can be neglected for further analysis.

\section{RESULTS}

In all three databases the general course of the curves was similar (Fig. 1)(Fig. 2)(Fig. 3).

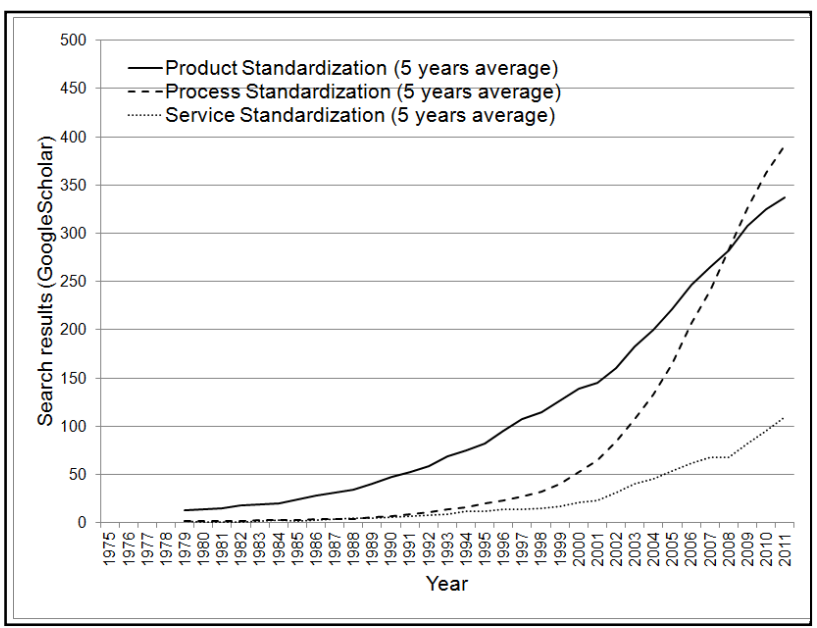

Fig. 1. Number of publications in Google Scholar

The literature analysis shows an increase of standardization research as the mentioned authors had assumed [10][13][19]. Additionally it could be established that intensity of research activities in three fields of standardization i.e. the number of publications referring to product, process or service standardization differed significantly over the years.

In the late eighties, product standardization research received an impulse from the publications of Davis, Greenstein, Farrell and Saloner. Their publications caused an increased awareness on product standardization which lead to many follow-up publications in this field and can be seen as the establishment of modern standardization research [4][5][6]. During the 90ies, a strong increase of research on product standardization can be observed. We suggest several reasons for this phenomenon: First, the increasing digital publishment of research may have lead to a higher amount of available publications online. Second, the increasing popularity of the concept of mass customization (see 3.1.) in the mid-nineties may have caused increased research activities in product standardization [11].

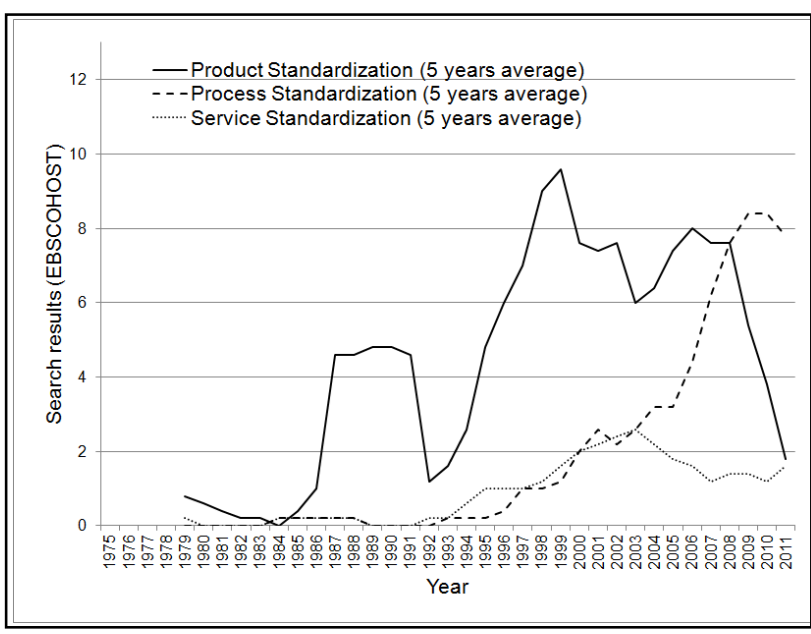

Fig. 2. Number of publications in Ebscohost

Product standardization dominated research over the 90ies, until rapidly increasing process standardization exceeded it in the between the years 2005 and 2006 in all three databases (the figures show a point of intersection shifted to 2007/2008 since a five years average was used in the illustrations). One reason for this may lie in several publications around the turn of the millennium, in which various authors described benefits and the economic potential of process standardization [13][14]. Their findings may have triggered further publications in the following years.

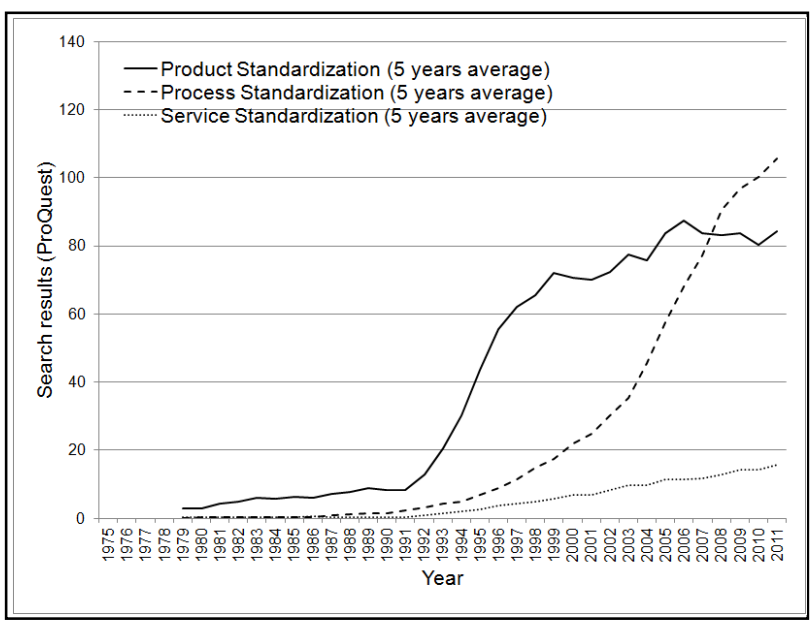

Fig. 3. Number of publications in ProQuest

In all three databases the number of publications on service standardization was much smaller than in product and process standardization. This may be explained by the fact that the subject óserviceô became more relevant only since the beginning of the new millennium [22]. Additionally, service standardization is seen to be a more difficult research subject than product or process standardization. However during the last years, a stronger growth can be observed.

Although, there are strong variations of the number of publications in the different portals (Ebscohost had at most 10 publications per annum, while Google Scholar had nearly 400 in 2011), the general trend is similar, as even the point of intersection of product and process standardization is in the same year in all three databases. 


\section{CONCLUSION}

We could verify that research on standardization in general is rapidly increasing. But there are differences in the intensity of research activities between the subdisciplines product, process and service standardization.

Product standardization was the dominating research topic for several decades, until the number of publications addressing process standardization showed a strong increase in the late 90ies. Since around 2005 it exceeds those related to product standardization. So we can confirm Muenstermanns assumption that research on process standardization is on the advance [13].

The field of service standardization is rising slowly. However, regarding the increasing importance of services in society and economics, service standardization has the potential to become the dominating research field in future. In that issue, it is suggested that the different communities interested in standardization seem to be moving closer together to "establish a systematic view of the domain and to incorporate diverse research strands into a common view." [25].

\section{LIMITATIONS}

The content of the analyzed publications was not checked in detail, but for five years of research the importance of the literature for the standardization topic was analyzed. About $10 \%$ of the publications were not in focus, but as the share of these out of focus publications is almost equal over the years, in each database and for each topic their influence on the quality of the results can be neglected.

Not regarded was the possibility that especially older publications are not considered since they have not been digitalized yet and thus are not available online. This may cause that the total number of publication may be higher in the 70ies, 80ies and early 90ies. However, the ratio of publications in the research fields should not be affected.

\section{OUTLOOK}

To gain a better understanding of the activities in the research fields of product, process and service standardization further studies will be conducted.

As the results of the analysis were just checked about their general relation to the topic standardization of products, processes or services, a detailed meta-analysis of the published literature will expose more detailed correlations between the different fields of standardization research.

In this study we focused only on the number of publications, no matter if they had an academic or industrial background. In further research this background shall be considered.

\section{REFERENCES}

[1] Hesser, W. (2006). Standardization within a company, In: Standardisation in Companies and Markets, Hesser, W. (Ed.), de Fries, H., Feilzer A., pp. 177-216, Helmut-Schmidt-University, ISBN: 978-3-000185-22-9, Hamburg
[2] Perera, H. S. C., Nagarur, N., Tabucanon, M. T. (1999). Component part standardization: A way to reduce the life-cycle costs of products. International Journal of Production Economics, Vol. 60ñ61, 20 April 1999, pp. 109ñ116

[3] Russell, A. L. (2005). Standardization in History: A Review Essay with an Eye to the Future, In: The Standards Edge: Future Generations, Bolin, S. (Ed.), pp. 247-260, Ann Arbor

[4] David, P. A. (1987). Some new standards for the economics of standardization in the information age. In: Economic Policy and Technological Performance. Dasgupta, P., Stoneman P. (Eds.) Cambrige University Press, London

[5] Farrell, J. \& Saloner, G. (1985). Standardization, Compatiblity, and Innovationô, The RAND Journal of Economics, Vol. 16, No. 1, pp. 70-83, Dept. of Economics, MIT, Cambridge

[6] Langenberg, T. (2006). Standardization and Expectations (Lecture Notes in Economics and Mathematical Systems), Springer-Verlag Berlin, ISBN: 978-3-540-28112-2, Heidelberg

[7] Gepp, M.; Horn, S.; Amberg, M. (2012). Towards a systematization of standardization. Proceedings International Confererence on Business and Management, Izmir, in press

[8] EN (2006). Standardization and related activities - General vocabulary, Trilingual version, EN 45020:2006

[9] United Nations Industrial Development Organisation UNIDO (2006). Role of Standards - A Guide for small and medium-sized enterprises, Working Paper

[10] Tassey, G. (2000). Standardization in technology-based markets, Research Policy, pp. 587ñ602, Vol. 29, Iss. 4-5.

[11] Kotha, S. (1995). Mass customization: implementing the emerging paradigm for competitive advantage, Strategic Management Journal, Special Issue: Technological Transformation and the New Competitive Landscape, pp. 21-42

[12] Davis, S. (1987). Future Perfect, Addison-Wesley, Reading, MA

[13] Muenstermann, B. \& Weitzel, T. (2008). What Is Process Standardization?, Proceedings International Conference on Information Resources Management, 05.01.2008, paper 64

[14] Wuellenweber, K., Koenig, W., Beimborn D., Weitzel T. (2009) The Impact of Process Standardization on Bussiness Process Outsourcing Success, In: Information Systems Outsourcing, Hirschheim, R., Heinzl, A., Dibbern, J. (Eds.), pp. 527-548, Springer, ISBN: 978-3-540-88850-5, Berlin

[15] Large Industrial Plant Manufacturerös Group VDMA (2010). Large industrial plant manufacturing - Industry concerned about the future, Status Report 2009/2010, VDMA, Frankfurt

[16] Stypmann, M. (2009), Dienstleistungsstandards in erfolgreichen Internationalisierungsstrategien (Service standards in successful internationalization strategies), In: Dienstleistungsstandards in erfolgreichen Internationalisierungsstrategien, ISBN: 978-3-41017015-0, Beuth-Verlag, Berlin

[17] Normann, R. (2000), Service Management: Strategy and Leadership in Services Business, $3^{\text {rd }}$ Edition, Wiley

[18] Jazdi, N., Maga, C., Eben, T. (2010). Improved systematisation in plant engineering and industrial solution business $\tilde{n}$ increased efficiency through domain engineering, at Automatisierungstechnik, pp. 524-532, Vol. 58, No. 8

[19] Blind, K. (2004). The economics of standards. Theory, evidence, policy. Elgar, Cheltenham

[20] Ramakumar, A., Cooper, B. (2004). Process standardization proves profitable. Quality, Vol. 43, No. 2, pp. $42 \tilde{n} 45$

[21] Manrodt, K. B. \& Vitasek, J. (2004). Global process standardization: A case study. Journal of Business Logistics, Vol. 25 , No. 1, pp. 1-23

[22] Reichwald et al (2009), Service Standardization, CLIC Executive Briefing Note No. 012, ISSN: 1866-41, Center for Leading Innovation \& Cooperation (CLIC), Leipzig

[23] Mikki S. (2009). Google Scholar Compared to Web of Science: A Literature Review, Nordic Journal of Information Literarcy in higher Education, Vol. 1, Iss. 1, pp. 41-51

[24] Neuhaus, C., Neuhaus, E., Asher, A., \& Wrede, C. (2006). The Depth and Breadth of Google Scholar: An Empirical Study. portal: Libraries and the Academy, Vol. 6, No. 2, pp. 127-141 Johns Hopkins University Press, Baltimore

[25] Weitzel et al (2006) A Unified Economic Model of Standard Diffusion: The Impact of Standardization Cost, Network Effects \& Network Topology, MISQ, Vol. 30 Special Issue, pp. 489-514 